\title{
Synthesis, characterization, spectroscopy and biological activity of 4-((3-formyl-4-hydroxyphenyl)azo)-1-alkylpyridinium salts
}

\author{
SAKINEH OMIDI ${ }^{\mathrm{a}}$, VIDA KHOJASTEH ${ }^{\mathrm{a}}$, ALI KAKANEJADIFARD ${ }^{\mathrm{a}, *}$, \\ MOTALEB GHASEMIAN ${ }^{\mathrm{a}}$ and FARIDEH AZARBANI ${ }^{\mathrm{b}}$ \\ a Department of Chemistry, Faculty of Science, Lorestan University, Khorramabad, Iran \\ ${ }^{b}$ Department of Biology, Faculty of Science, Lorestan University, Khorramabad, Iran \\ E-mail: ali.kakanejadifard@gmail.com; kakanejadi.a@lu.ac.ir
}

MS received 30 December 2017; revised 24 April 2018; accepted 20 June 2018; published online 2 August 2018

\begin{abstract}
The reaction of 2-hydroxy-5-(pyridine-4-yldiazenyl)benzaldehyde with n-alkyl bromides generated five novel azo pyridinium salts in good to excellent yields. The ${ }^{1} \mathrm{H}$ and ${ }^{13} \mathrm{C}$ NMR and UV-Vis absorption spectra indicated several tautomers for the new compounds. The NMR, UV-Vis absorption spectra and quantum chemical calculations show that the azo pyridinium salts have a new resonant structure compared to the corresponding azo precursor. Antibacterial activity was studied by disc diffusion and MIC methods. Diphenylpicrylhydrazyl (DPPH) assay was used to determine the antioxidant properties. The effects of carbon chain length on antimicrobial activity were also investigated. The results showed that existence of alkyl groups is crucial for the antibacterial properties. The new compound with decyl group displayed the best antibacterial activity.
\end{abstract}

Keywords. Azo compounds; pyridinium quaternary salts; antibacterial activity; theoretical study.

\section{Introduction}

Azo compounds cover a major portion of industrial dyes, as aromatic azo compounds are largely colored. ${ }^{1-3}$ The rich chemistry of azo compounds is related to several important biological properties such as antibacterial, antifungal, antitumor and antioxidant activities. ${ }^{4-6}$ Also, azo compounds are utilized as therapeutic agents and can be used to image amyloid plaques in the brains of Alzheimer's patients. ${ }^{7}$

Some azo dyes are also applied in drugs and cosmetics. ${ }^{8}$ Azobenzenes display a reversible isomerization between trans and cis isomers by diverse stability and this feature is used in the development of photomechanical processes and medical fields. ${ }^{9-11}$ Heterocyclic moieties, such as pyridine have been utilized for the synthesis of new azo dyes to enhance their color strength and brilliant shades. ${ }^{12,13}$ Azo pyridine derivatives have a wide range of biological activities. For example, phenazopyridine, with the trade name of 'pyridium', is used as a urinary analgesic. ${ }^{14}$
Long alkyl chain quaternary ammonium compounds (QACs) exert a broad range of antibacterial activity against Gram-positive and Gram-negative bacteria, some pathogenic species of fungi and protozoa. ${ }^{15,16}$ The amphiphilic nature of QACs, are concurrently exploited for their surfactant, preserving and antimicrobial properties in some cosmetic and personal care products. ${ }^{17,18}$ Structural aspects and a variety of biological activities of azo compounds and quaternary pyridinium salts were a motivation for the synthesis of five new azo compounds containing long chain alkyl pyridinium salts for the studies of antibacterial and antioxidant properties.

\section{Experimental}

\subsection{Materials and measurements}

All the chemicals, reagents, and solvents were purchased from Merck (Germany) and used without further purification. The solvents used in the reactions were analytically reagent grade. 2-Hydroxy-5-(pyridine-4-yldiazenyl)benzaldehyde (1) was

\footnotetext{
*For correspondence

Electronic supplementary material: The online version of this article (https://doi.org/10.1007/s12039-018-1521-5) contains supplementary material, which is available to authorized users.
} 
prepared and purified according to the method reported in the literature. ${ }^{19}$ Melting points were measured on an Electrothermal 9200 apparatus. Mass spectra were recorded on an Agilent MS Model 5973. FT-IR spectra were recorded on a Shimadzu $8400 \mathrm{~S}$ spectrometer using $\mathrm{KBr}$ disc. The electronic absorption spectra were recorded with a Shimadzu 1650 spectrophotometer. ${ }^{1} \mathrm{H}$ and ${ }^{13} \mathrm{C}$ NMR spectra were recorded in DMSO- $\mathrm{d}_{6}$ as the solvent on the Bruker DRX-300 MHz and $400 \mathrm{MHz}$ Advance spectrometers.

\subsection{General procedure for the synthesis of 4-((3-formyl-4-hydroxyphenyl)azo)-1-alkylpyridinium bromide $(\mathbf{2} \mathbf{a}-\mathbf{e})$}

To a stirring solution of 2-hydroxy-5-(pyridine-4-yldiazenyl) benzaldehyde (1, $10 \mathrm{mmol}, 2.27 \mathrm{~g}$ ) in ethanol $(200 \mathrm{~mL})$, was added the relevant alkyl bromide $(12 \mathrm{mmol})$ at $78^{\circ} \mathrm{C}$. The mixture was stirred and refluxed for $24 \mathrm{~h}$, and the solvent was removed. The resultant solid material was collected and washed with cold diethyl ether and dried. The products are soluble in acetonitrile dimethylsulfoxide (DMSO), $N, N^{\prime}$ dimethylformamide (DMF), methanol $\left(\mathrm{CH}_{3} \mathrm{OH}\right)$, ethanol $\left(\mathrm{C}_{2} \mathrm{H}_{5} \mathrm{OH}\right),\left(\mathrm{CH}_{3} \mathrm{CN}\right)$ and tetrahydrofuran $(\mathrm{THF})$, (see Supplementary Information).

\subsection{Compound 4-((3-formyl-4-hydroxyphenyl)azo)-1- methylpyridinium iodide (2a)}

Maroon solid. Yield: $88 \%$; M.p.: $242-244^{\circ} \mathrm{C}$. IR $\left(\mathrm{cm}^{-1}\right)$ : $\nu \mathrm{OH} 3475, v \mathrm{CH}_{\text {aliphatic }} 2920, v \mathrm{CH}=\mathrm{O} 2736, v \mathrm{C}=\mathrm{O} 1654$, $\nu \mathrm{N}=\mathrm{N} 1600, v \mathrm{C}=\mathrm{C} 1488, v \mathrm{C}-\mathrm{O} 1278 ;{ }^{1} \mathrm{H} \mathrm{NMR}(\delta, \mathrm{ppm}$ in DMSO-d6): 10.39-10.19 (s,1H, CHO), 8.78 and 8.56, 8.54 $(\mathrm{d}, 2 \mathrm{H}, \mathrm{J} / \mathrm{Hz} 6.60), 8.21,8.20$ and $7.80,7.99(\mathrm{~d}, 1 \mathrm{H}, \mathrm{J} / \mathrm{Hz}$ 2.43), 8.12, 8.11, 8.09, 8.08 and 7.88, 7.87, 7.85, 7.84 (dd, $\left.1 \mathrm{H},{ }^{3} \mathrm{~J} / \mathrm{Hz} 9.71,{ }^{5} \mathrm{~J} / \mathrm{Hz} 2.46\right), 7.81,7.79$ and $7.71(\mathrm{~d}, 2 \mathrm{H}$, $J / \mathrm{Hz} 6.63), 7.18,7.15$ and $6.41,6.38(\mathrm{~d}, 1 \mathrm{H}, J / \mathrm{Hz} 9.72)$, 4.11 and $3.66(\mathrm{~s}, 3 \mathrm{H}) ;{ }^{13} \mathrm{C} \mathrm{NMR}$ ( $\delta$, ppm in DMSO-d6): 190.72 and 190.26, 182.96, 165.27, 162.06, 145.10, 144.33, $141.48,129.84,127.52,126.20,125.18,122.80,119.03$, 116.19 and $45.75\left(\mathrm{CH}_{3}\right)$; HR-MS (EI-MS) $\mathrm{m} / \mathrm{z}$ calc. for $\mathrm{C}_{13} \mathrm{H}_{12} \mathrm{IN}_{3} \mathrm{O}_{2}(\mathrm{M}+\mathrm{H}+18)^{+} 388.17$, found 388.3 and HR-MS (EI-MS) $\mathrm{m} / \mathrm{z}$ calc. for $\mathrm{C}_{13} \mathrm{H}_{11} \mathrm{~N}_{3} \mathrm{O}_{2}(\mathrm{M}-\mathrm{H}-\mathrm{I})^{+} 241.25$, found 241.4 .

2.3a Compound 4-((3-formyl-4-hydroxyphenyl)azo)1-decylpyridinium bromide (2b): Dark brown solid. Yield: $89 \%$; M.p.: $265^{\circ} \mathrm{C}$. IR $\left(\mathrm{cm}^{-1}\right)$ : vOH 3432, vCH $\mathrm{CH}_{\text {aliphatic }}$ 2925, 2854, vCH=O 2736, 2854, $v \mathrm{C}=\mathrm{O} 1663, v \mathrm{~N}=\mathrm{N} 1594$, $\nu \mathrm{C}=\mathrm{C} 1484, v \mathrm{C}-\mathrm{O} .1267 ;{ }^{1} \mathrm{H}$ NMR $(\delta, \mathrm{ppm}$ in DMSO-d6): 10.38-10.10 (s,1H, C부), 8.75-8.65 (bs, 2H), 8.01, 8.00 $(\mathrm{d}, 1 \mathrm{H}, \mathrm{J} / \mathrm{Hz} 2.16), 7.87,7.85,7.80,7.79\left(\mathrm{dd}, 1 \mathrm{H},{ }^{3} \mathrm{~J} / \mathrm{Hz}\right.$ $\left.9.34,{ }^{5} \mathrm{~J} / \mathrm{Hz} 2.17\right), 7.55(\mathrm{~d}, 2 \mathrm{H}) ; 6.57,6.54(\mathrm{~d}, 1 \mathrm{H}, \mathrm{J} / \mathrm{Hz}$ 9.3), 4.33 and 4.15 (t, 2H); 1.78-1.72 (m, 2H), 1.36-1.12 (bs, $14 \mathrm{H}), 0.76(\mathrm{t}, 3 \mathrm{H}) ;{ }^{13} \mathrm{C}$ NMR ( $\delta$, ppm in DMSO-d6): 191.20, $183.34,177.66,162.34,157.58,151.52,151.02,144.41$, $141.64,139.57,133.25,127.80,126.82,126.32,125.24$,
$123.74,116.62,115.61,31.36,30.67,28,94,28.74,28.50$, 25.53, 22.182, 22.182 and 14.03; HR-MS (EI-MS) m/z calc. for $\mathrm{C}_{22} \mathrm{H}_{30} \mathrm{BrN}_{3} \mathrm{O}_{2}(\mathrm{M}+18)^{+} 466.41$, found 466 and $\mathrm{HR}$ MS (EI-MS) m/z calc. for $\mathrm{C}_{22} \mathrm{H}_{29} \mathrm{~N}_{3} \mathrm{O}_{2}(\mathrm{M}-\mathrm{H}-\mathrm{Br})^{+} 367.50$, found 368 .

2.3b Compound 4-((3-formyl-4-hydroxyphenyl)azo)1-dodecylpyridinium bromide (2c): Maroon solid. Yield: 90\%; M.p.: 276-278 ${ }^{\circ} \mathrm{C}$; IR $\left(\mathrm{cm}^{-1}\right): v \mathrm{OH} 3391, v \mathrm{CH}_{\text {aliphatic }}$ $2925,2854, v \mathrm{CH}=\mathrm{O} 2736,2854, v \mathrm{C}=\mathrm{O} 1663, v \mathrm{~N}=\mathrm{N} 1596$, $v \mathrm{C}=\mathrm{C} 1484, v \mathrm{C}-\mathrm{O} 1267 ;{ }^{1} \mathrm{H}$ NMR $(\delta, \mathrm{ppm}$ in DMSO-d6): 10.38-10.16 (s, 1H, CH=O), 8.67-8.64 (d, 2H), 8.04, 8.03 (d, $1 \mathrm{H}, \mathrm{J} / \mathrm{Hz} 2.28), 7.88,7.87,7.85,7.84$ (dd, $1 \mathrm{H},{ }^{3} \mathrm{~J} / \mathrm{Hz} 9.34$, $\left.{ }^{5} \mathrm{~J} / \mathrm{Hz} 2.19\right), 7.58-7.56$ (d, 2H, $\left.J / \mathrm{Hz} 5.89\right)$; 6.66-6.63 (d, $1 \mathrm{H}$, $J / \mathrm{Hz}$ 9.30), 4.40-4.25 (t, 2H), 1.77-1.73 (m, 2H), 1.17 (bs, $18 \mathrm{H}) ; 0.80(\mathrm{t}, 3 \mathrm{H}) ;{ }^{13} \mathrm{C}$ NMR $(\delta, \mathrm{ppm}$ in DMSO-d6): 190.71, $183.37,175.63,162.35,157.37,151.49,151.01,144.23$, $141.62,140.20,131.30,127.26,126.33,124.07,123.52$, $116.36,115.92,115.50,32.27,31.33,29.05,28.99,28.92$, 28.76, 28.15, 27. 54, 22.14 and 13.97; HR-MS (EI-MS) $\mathrm{m} / \mathrm{z}$ calc. for $\mathrm{C}_{24} \mathrm{H}_{34} \mathrm{BrN}_{3} \mathrm{O}_{2}(\mathrm{M}+\mathrm{H})^{+} 477.45$, found 477.2 and HR-MS (EI-MS) m/z calc. for $\mathrm{C}_{24} \mathrm{H}_{33} \mathrm{~N}_{3} \mathrm{O}_{2}(\mathrm{M}-\mathrm{H}-\mathrm{Br})^{+}$ 395.54, found 396 .

2.3c Compound 4-((3-formyl-4-hydroxyphenyl)azo)1-tetradecylpyridinium bromide (2d): Brown solid. Yield: 90\%; M.p.: 288-289 ${ }^{\circ} \mathrm{C}$; IR $\left(\mathrm{cm}^{-1}\right)$ : $\nu \mathrm{OH} 3457$, $\nu \mathrm{CH}_{\text {aliphatic }} 2925,2854, \nu \mathrm{CH}=\mathrm{O} 2736,2854, \nu \mathrm{C}=\mathrm{O} 1663$, $\nu \mathrm{N}=\mathrm{N} 1599, \nu \mathrm{C}=\mathrm{C} 1481, \nu \mathrm{C}-\mathrm{O} 1267 ;{ }^{1} \mathrm{H} \mathrm{NMR}(\delta, \mathrm{ppm}$ in DMSO-d6): 10.43-10.19 (s, 1H, CHO), 8.78, 8.76 and $8.73,8.71(\mathrm{~d}, 2 \mathrm{H}, \mathrm{J} / \mathrm{Hz} 6.80) ; 8.18$ and $8.03(\mathrm{~d}, 1 \mathrm{H}), 8.10-$ 8.05 and $7.92-7.87(\mathrm{dd}, 1 \mathrm{H}) ; 7.83,7.82$ and $7.70,7.69(\mathrm{~d}$, $2 \mathrm{H}, J / \mathrm{Hz} 6.80), 7.13,7.10$ and $6.42,6.39(\mathrm{~d}, 1 \mathrm{H}, J / \mathrm{Hz}$ 9.60), 4.42-4.38 (t, 2H); 1.90-1.80 (m, 2H), 1.4-1.1 (m, $22 \mathrm{H})$; $0.86-0.82(\mathrm{t}, 3 \mathrm{H}),{ }^{13} \mathrm{C}$ NMR $(\delta, \mathrm{ppm}$ in DMSO-d6): $190.99,183.35,177.10,162.35,157.57,151.00,144.38$, $141.65,139.59,133.12,126.74,126.37,125.07,123.66$, $116.39,115.46,31.37,30.66,29.09,28.87,28.79,28.49$, 25.48, 22.17 and 14.01. HR-MS (EI-MS) $\mathrm{m} / \mathrm{z}$ calc. for $\mathrm{C}_{26} \mathrm{H}_{38} \mathrm{BrN}_{3} \mathrm{O}_{2}(\mathrm{M}+\mathrm{H}+18)^{+}$523.51, found 523.6 and HRMS (EI-MS) m/z calc. for $\mathrm{C}_{26} \mathrm{H}_{37} \mathrm{~N}_{3} \mathrm{O}_{2}(\mathrm{M}-\mathrm{H}-\mathrm{Br})^{+} 423.59$, found 423.4 .

2.3d Compound 4-((3-formyl-4-hydroxyphenyl)azo)1-hexadecylpyridinium bromide (2e): Brown solid. Yield: $91 \%$, M.p.: $>300^{\circ} \mathrm{C}$; $\mathrm{IR}\left(\mathrm{cm}^{-1}\right) ; \nu \mathrm{OH} 3319, \nu \mathrm{CH}_{\text {aliphatic }}$ $2925,2854, v \mathrm{CH}=\mathrm{O} 2736,2854, v \mathrm{C}=\mathrm{O} 1670, v \mathrm{~N}=\mathrm{N} 1596$, $\nu \mathrm{C}=\mathrm{C} 1483, \nu \mathrm{C}-\mathrm{O} 1271 ;{ }^{1} \mathrm{H}$ NMR $(\delta, \mathrm{ppm}$ in DMSO-d6): 10.38-10.07 (s, 1H, CHO), 8.69, 8.67 and 8.62, $8.60(\mathrm{~d}$, $2 \mathrm{H}, J / \mathrm{Hz} 5.88 \mathrm{~Hz}), 8.00,7.99$ (d, 1H, J/Hz 2.7), 7.82, 7.81, 7.79, $7.78\left(\mathrm{dd}, 1 \mathrm{H},{ }^{3} \mathrm{~J} / \mathrm{Hz} 9.44,{ }^{5} \mathrm{~J} / \mathrm{Hz} 2.71\right), 7.55$, $7.53(\mathrm{~d}, 2 \mathrm{H}, J / \mathrm{Hz} 5.94) ; 6.52,6.49(\mathrm{~d}, 1 \mathrm{H}, J / \mathrm{Hz} 9.45)$, 4.41-4.33 (t, 2H); 1.79-1.72 (m, 2H), 1.29-1.06 (m, 26H), $0.81-0.76(\mathrm{t}, 3 \mathrm{H}),{ }^{13} \mathrm{C}$ NMR $(\delta, \mathrm{ppm}$ in DMSO-d6): 191.04, $183.29,178.06,162.39,157.58,150.91,144.27,141.60$, $139.17,133.76,126.50,126.31,125.49,123.69,116.39$, $115.39,31.30,30.57,29.05,28.88,28.78,28.72,28.40$, 
25.43, 22.10 and 13.95; HR-MS (EI-MS) $\mathrm{m} / \mathrm{z}$ calc. for $\mathrm{C}_{28} \mathrm{H}_{42} \mathrm{BrN}_{3} \mathrm{O}_{2}(\mathrm{M})^{+}$532.56, found 532 and HR-MS (EIMS) $\mathrm{m} / \mathrm{z}$ calc. for $\mathrm{C}_{28} \mathrm{H}_{41} \mathrm{~N}_{3} \mathrm{O}_{2}(\mathrm{M}-\mathrm{H}-\mathrm{Br})^{+} 451.65$, found 452 .

\subsection{Antibacterial activity}

The derivatives $\mathbf{2 a - e}$ were screened for their antibacterial activity against Bacillus cereus (PTCC 1556), Staphylococcus aureus (PTCC 1112), Escherichia coli (PTCC 1330) and Klebsiella pneumonia (PTCC 1053) by the disc diffusion method. ${ }^{20}$ Muller Hinton agar plates were inoculated with the $24 \mathrm{~h}$ cultures of bacteria. The synthesized derivatives were dissolved in DMSO and placed on the surface of the inoculated plates at the concentration of $30 \mu \mathrm{g} / \mathrm{disc}$. Amikacin was used as the standard antibiotic. After incubation at $37^{\circ} \mathrm{C}$ for $24 \mathrm{~h}$, the diameter of inhibition zone was measured $(\mathrm{mm})$. The minimum inhibitory concentration (MIC) values were also determined using the broth micro dilution method. ${ }^{21}$

\subsection{Free radical scavenging activity}

The free radical scavenging activity of the derivatives $\mathbf{2 a -}$ e was determined using Diphenylpicrylhydrazyl (DPPH) method. ${ }^{22} 50 \mu \mathrm{L}$ of sample in DMSO $(1 \mathrm{mg} / \mathrm{mL})$ was mixed with $5 \mathrm{~mL}$ of DPPH $(0.004 \%$ in methanol). The mixture was then vortexed vigorously and incubated in the dark at room temperature for $30 \mathrm{~min}$. The absorbance was read at $517 \mathrm{~nm}$ against the blank. The radical scavenging activity (RSA) was calculated using the following formula:

$\% \mathrm{RSA}=\left[\left(\mathrm{A}_{\mathrm{C}}-\mathrm{A}_{\mathrm{S}}\right) / \mathrm{A}_{\mathrm{C}}\right] \times 100$

Where, $A_{C}$ is the absorbance of DPPH solution without sample as control and $A_{S}$ is the absorbance of DPPH in the Presence of the sample. The results were compared to Ascorbic acid (Vitamin C) as standard. The $\mathrm{IC}_{50}$ value was calculated graphically based on the capacity of compound concentration to scavenge $50 \%$ of free radicals.

\subsection{Quantum chemical calculations}

The structural parameters of compounds evaluated by quantum chemical calculations using the Gaussian 03 program. ${ }^{23}$ The gas phase geometries of $\mathbf{2 a}$ were optimized using the DFT (B3LYP) method with the 6-311++G (2d, 2p) basis set. Harmonic frequency calculations were performed at all the stationary points to characterize its nature and to ensure that the optimized structure corresponds to a global minimum. The vibrational band assignments were made using the Gauss-View molecular visualization program. ${ }^{24}$ Electronic excitations of the title compound were calculated by using TD-DFT for the gas phase. ${ }^{25,26}$

\section{Results and Discussion}

The azo pyridinium salts 4-((3-formyl-4-hydroxyphenyl)diazenyl-1-alkylpyridinium salts (2a-e) were prepared by the reaction of 2-hydroxy-5-(pyridine-4yldiazenyl)benzaldehyde (1) with related n-alkyl bromides in ethanol (Figure 1a). Compounds 2a-e are air-stable and soluble in THF, EtOH, $\mathrm{CH}_{3} \mathrm{CN}$, DMSO and DMF. The structures of $\mathbf{2 a - e}$ were characterized by elemental analysis, mass, FT-IR, UV-Vis, ${ }^{1} \mathrm{H}$ and ${ }^{13} \mathrm{C}$ NMR spectroscopy. Compounds 2a-e were tested for antibacterial and antioxidant properties.

\subsection{Spectral characterization}

The FT-IR spectra of $\mathbf{1}$ and $\mathbf{2 a - e}$ are shown in supplementary information. After alkylation of $\mathbf{1}$, two sharp peaks appeared in 2925 and $2854 \mathrm{~cm}^{-1}$ which correspond to the n-alkyl chain.

The ${ }^{1} \mathrm{H}$ NMR spectra of 2a-e exhibited the $\mathrm{CH}=\mathrm{O}$ proton signals at 10.19-10.07 ppm. The aromatic and aliphatic protons appeared at $8.75-6.38 \mathrm{ppm}$ and 4.40 0.76 ppm, respectively. The ${ }^{13}$ CNMR spectra of $\mathbf{2 a - e}$ showed two peaks for carbonyl (191.20-190.71 and 183.37-182.96 ppm) and more than 10 peaks for aromatic carbons (178.06-115.39 ppm). The signals for the aliphatic carbons appeared at 45.74-13.95 ppm (Figures S2-S20 in Supplementary Information). Precise review of ${ }^{1} \mathrm{H}$ and ${ }^{13} \mathrm{C}$ NMR spectra showed that there is more than one structure in solution for $\mathbf{2 a}-\mathbf{e}$. For example, in ${ }^{1} \mathrm{H}$ NMR spectrum for $\mathbf{2 d}$, there are three peaks for $\mathrm{C} \underline{\mathrm{H}}=\mathrm{O}$ proton and the protons of pyridine ring in addition to the two doublets at 8.73-8.71 ppm and 7.83-7.81 ppm showed two doublets at $8.78-8.76 \mathrm{ppm}$ and 7.70 $7.69 \mathrm{ppm}$. The ortho proton to phenol group showed two separated doublets at 7.13-7.10 ppm and 6.42-6.39 ppm. Other weak bands are also observed in the ${ }^{1} \mathrm{H}$ NMR spectrum of $\mathbf{2 d}$, which clearly confirm the existence of three structures. Figure $1 \mathrm{~b}$ displays three resonance structures for $\mathbf{2 a}-\mathbf{e}$ compounds. ${ }^{1} \mathrm{H}$ NMR spectrum of $\mathbf{2 d}$ and the proposed structures are shown in Figure 2. In the ${ }^{13}$ C NMR spectrum of $2 d$, two peaks appeared at 190.99 and $183.35 \mathrm{ppm}$ that can be attributed to the carbonyl group, which indicated there are two carbonyl groups in the solution (Figure S15, Supplementary Information). Accordingly, there are two or more structures for 2a-e compounds which are due to the keto-enol tautomerism and hydrogen transfer. The ratio of resonance structures for $\mathbf{2 a}-\mathbf{e}$, calculated by integral of $\mathrm{CH}=\mathrm{O}$ in ${ }^{1} \mathrm{H}$ NMR spectra, is presented in Table 1 . Also, to further explore the proposed structures, the ${ }^{1} \mathrm{H}$ NMR spectrum of $2 \mathbf{d}$ was obtained by adding $\mathrm{NaOH}$ to the NMR tube. After the $\mathrm{pH}$ value was increased, the pertinent signals of 
(a)

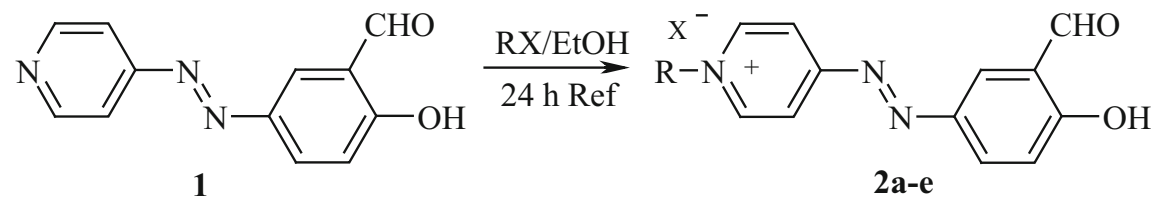

2a) $\begin{array}{lllllll}\mathrm{R} & =\mathrm{CH} 3 & \text { 2b) } & \mathrm{R}=\mathrm{C}_{10} \mathrm{H}_{23} & \text { 2c) } & \mathrm{R}=\mathrm{C}_{12} \mathrm{H}_{25} & \text { 2d) } \\ \mathrm{X} & \mathrm{R}=\mathrm{Br}, \mathrm{I}\end{array}$

(b)<smiles></smiles>

Figure 1. (a) The synthesis of compounds $2 \mathbf{2}-\mathbf{e}$. (b) The proposed resonant structures for $\mathbf{2 a - e}$.

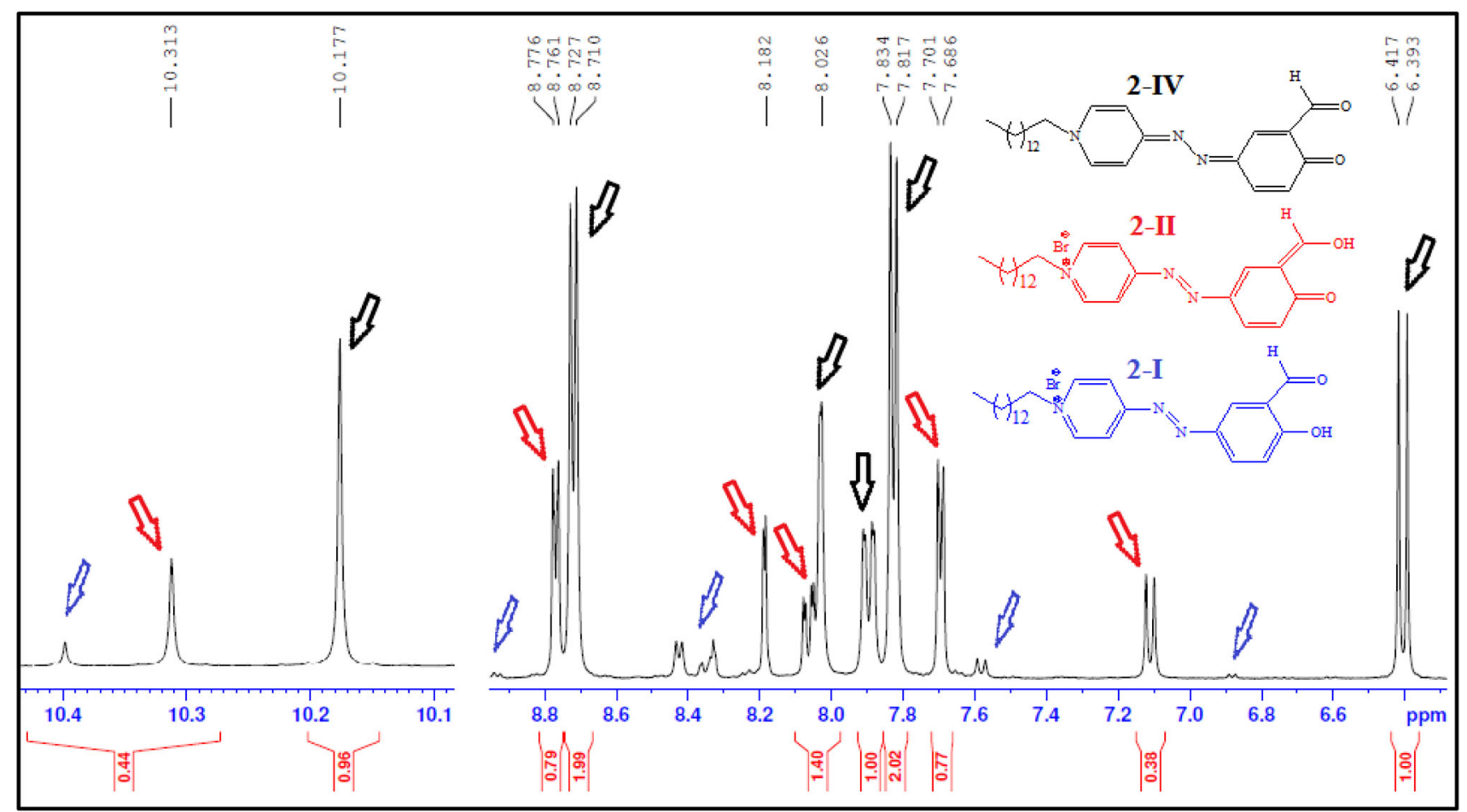

Figure 2. $\quad{ }^{1} \mathrm{H}$ NMR Spectrum of $\mathbf{2 d}$ (aromatic and aldehyde protons). 
Table 1. The ratio of resonance structures in the DMSO $(\%)$.

\begin{tabular}{lcc}
\hline Compound & 2-I and 2-II & 2-IV \\
\hline 2a & 37.28 & 62.72 \\
2b & 19.17 & 80.83 \\
2c & 22.26 & 77.74 \\
2d & 32.41 & 67.59 \\
2e & 18.15 & 81.15 \\
\hline
\end{tabular}

2-IV structure did not change, while the related signals of 2-I structure were deleted, and related signals to the 2-II structure have been shifted toward 2-IV signals. The shiftings are shown in Figure S14 (Supplementary Information) and attributed to partial dissociation of $\mathrm{O}-\mathrm{H}$ bond at 2-II structure by adding the $\mathrm{NaOH}$ solution. The chemical structures are supported by UV-Vis spectra, as well.

\subsection{Electronic absorption spectroscopy}

The electronic absorption spectra of the synthesized compounds were recorded (in the range of 200-600 nm) in solvents DMSO, DMF, MeOH, and THF $\left(2 \times 10^{-5} \mathrm{M}\right.$, $1 \mathrm{~cm}$, quartz cell) at room temperature (Table 2). The UV-Vis absorption spectra of $\mathbf{1}$ show a band at 226-264 nm that is assigned to $\pi \rightarrow \pi *$ transitions in the backbone of the aromatic ring. The second peak located at $349-422 \mathrm{~nm}$ is assigned to $\pi \rightarrow \pi^{*}$ electronic transition of the azo-aromatic chromophore. Furthermore, in the polar solvents of DMSO and DMF the third band at $450-481 \mathrm{~nm}$ is owing to $\mathrm{n} \rightarrow \pi^{*}$ electronic transition of the azo-aromatic chromophore and intramolecular hydrogen bonding. ${ }^{4,5}$

The UV-Vis absorption spectra of $\mathbf{2 a - e}$ in DMSO, $\mathrm{DMF}, \mathrm{MeOH}$, and THF solvents show a band at $219-268 \mathrm{~nm}$ that is assigned to $\pi \rightarrow \pi^{*}$ transitions in the backbone of the aromatic ring and displays bathochromic shift (positive solvatochromism) with polarity change of solvent. 2a-e in $\mathrm{MeOH}$ and THF solvents show a band at $365-437 \mathrm{~nm}$ that is assigned to $\pi \rightarrow \pi^{*}$ electronic transition of azo-aromatic chromophore. In the DMSO and DMF solvents mainly two bands are displayed. The first band located at $385-405 \mathrm{~nm}$ is because of $\pi \rightarrow \pi^{*}$ transition of the aromatic ring while the second one at $475-486 \mathrm{~nm}$ is owing to intramolecular hydrogen bonding between the hydroxyl and carbonyl groups and it indicated the ketoenol tautomerism in compounds $\mathbf{2 a - e}$ such as the whole of salicylaldehyde-based azo dyes. ${ }^{19,27}$ The absorption spectra of 2d in DMF, DMSO, THF, and $\mathrm{MeOH}$ with diverse salvation characters are shown in Figure $3 \mathrm{a}$.

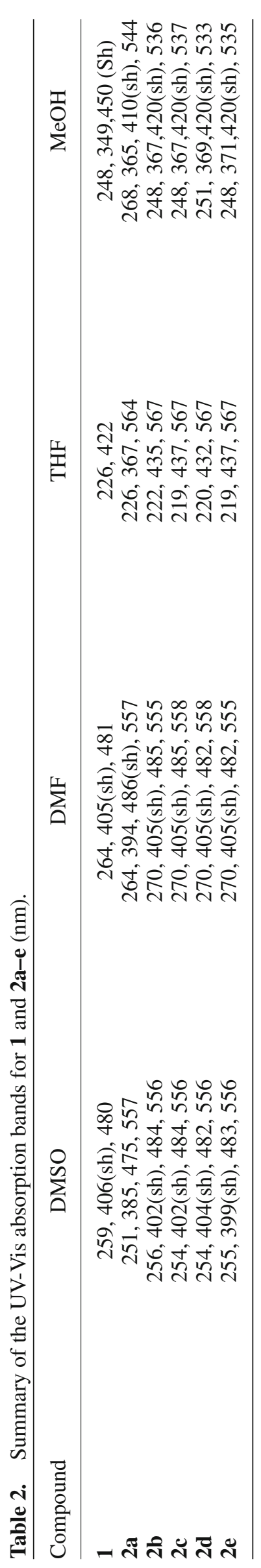


For $\mathbf{2 a - e , ~ c o m p a r e d ~ w i t h ~} \mathbf{1}$, there is an additional band at 533-567 nm in all of the solvents (Figures S21-S24 in Supplementary Information). The observed new peak is assumed to be associated with the development of appreciable 2-IV conformer. This is in line with obtained results by ${ }^{1} \mathrm{H},{ }^{13} \mathrm{C}$ NMR and further confirmed by measuring the absorption properties in basic solutions. The absorption spectrum of $\mathbf{2 d}$ was measured at different $\mathrm{pH}$ values (Figure S25 in Supplementary Information). As the $\mathrm{pH}$ value of the solution increased, the intensity of the band at 533-567 nm also increased. Dissociation of the phenolic proton results in the formation of 2-IV tautomer. State "2-IV" is more favorable to form a conjugate structure than states "2-I" and "2-II". Therefore the longest red shift in the visible spectrum (533-567 nm) is observed for $\mathbf{2 - I V} .{ }^{28}$ For further study about resonant structures; the Quantum chemical calculations were also done.

\subsection{Quantum chemical calculations}

To authenticate the electronic spectra of the compounds 2a-e, TD-DFT calculations on electronic absorption spectra in the gas phase were performed. The maximum absorption peak $\left(\lambda_{\max }\right)$ in a UV-Vis spectrum corresponds to vertical excitation. TD-DFT calculations predict absorption bands with different UV-Vis regions for 2-III and 2-IV tautomers (Figure 3b). The absorption region of $\mathbf{2}$-IV form is different than the $\mathbf{2}$-III. It shows that 2-IV has the longest wavelength of absorption in the electronic spectra. Hence, by comparing the calculated values of wavelengths with experimental data, it can be concluded that $\mathbf{2}$-IV state could be the predominant tautomer in 2a-e compounds in both solvent and gas phases (Figure 3 and Table 2).

The selected optimized geometric parameters for 2-III and 2-IV tautomers are listed in Table S1 for comparison (Figure S26) in Supplementary Information. There are some notable points in these results. In both structures, the torsion angles for $\mathrm{N}_{11}-\mathrm{N}_{12}-\mathrm{C}_{13}-\mathrm{C}_{14}$, $\mathrm{C}_{6}-\mathrm{N}_{11}-\mathrm{N}_{12}-\mathrm{C}_{13}, \mathrm{C}_{5}-\mathrm{C}_{6}-\mathrm{N}_{11}-\mathrm{N}_{12}$, and $\mathrm{C}_{3}-\mathrm{C}_{4}-\mathrm{C}_{9}-\mathrm{O}_{10}$ are ca. $180^{\circ}$ or $0^{\circ}$. This indicates that the two aromatic rings and $\mathrm{N}=\mathrm{N}$ and $\mathrm{C}=\mathrm{N}$ bonds are planar and that it allows the $\pi$ electron conjugation to extend throughout the aromatic rings.

The calculated stretching frequency of $\mathrm{C}=\mathrm{O}$ and $\mathrm{N}=\mathrm{N}$ bonds are found to be $1670-1780 \mathrm{~cm}^{-1}$ and 1520 $1089 \mathrm{~cm}^{-1}$, respectively, which agree with the experimental data (Table S1 and Figures S2-S5 in Supplementary Information). Furthermore, the $\mathrm{O}_{10} \cdots \mathrm{H}_{1}$ bond distance in the optimized structures of 2-III is $1.793 \AA$. This distance is shorter than the sum of van der Waals radii of oxygen $(1.52 \AA)$ and hydrogen
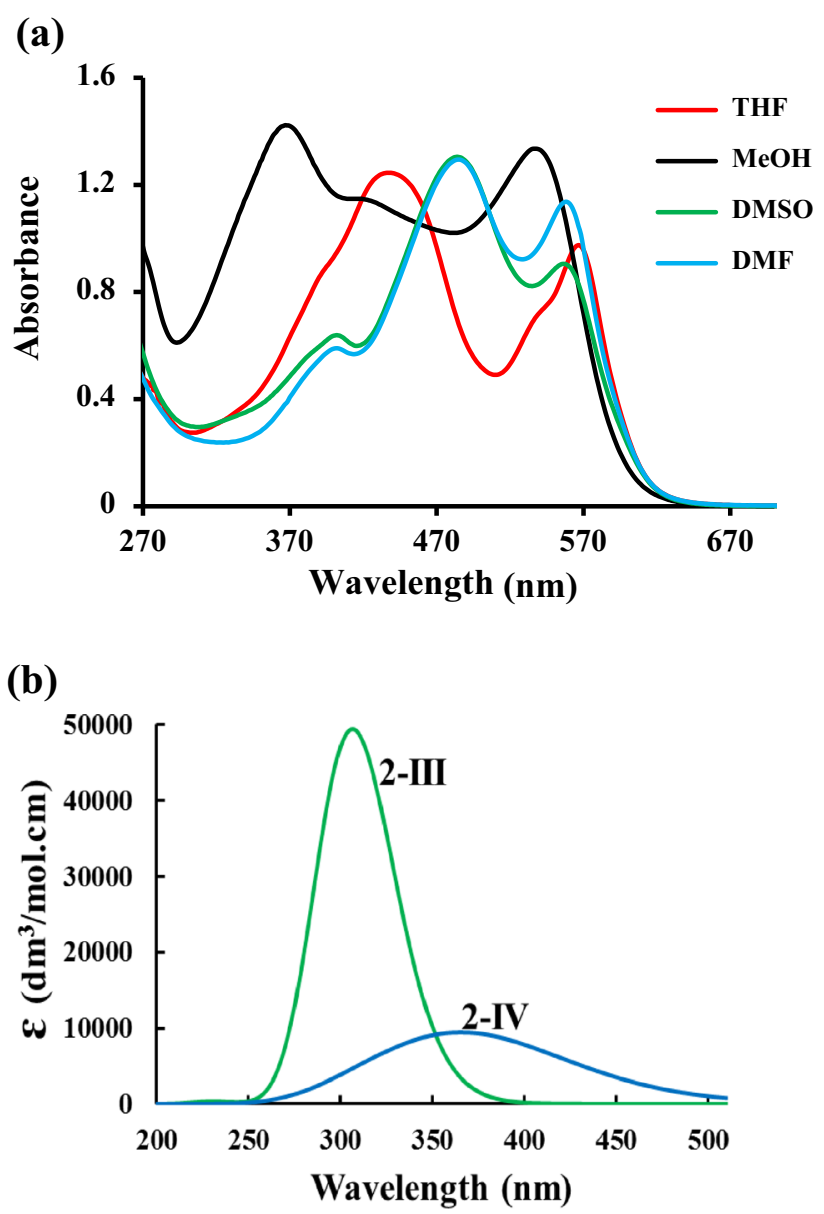

Figure 3. (a) Absorption spectra of 2d in DMF, DMSO, $\mathrm{MeOH}$ and THF solvents $\left(5 \times 10^{-5} \mathrm{M}, 1 \mathrm{~cm}\right.$, quartz cell). (b) The computed electronic spectra for 2-III and 2-IV.

(1.20 $\AA$ ) atoms indicating the presence of hydrogen bonding interactions.

\subsection{Biological activities}

Compounds 2a-e were tested in vitro for antibacterial activity against $S$. aureus, B. cereus, E. coli and $K$. pneumonia. The results indicate that all of the prepared compounds had antibacterial activities against Grampositive bacteria (S. aureus and B. cereus) (Figure 4), but they exhibited no activity against Gram-negative bacteria (E. coli and $K$. pneumonia). It is observed that compound $\mathbf{1}$ and $\mathbf{2 a}$ show weak activity while $\mathbf{2 b - e}$ display good activity against Gram-positive bacteria. These results show that the presence of the carbon chain is necessary to achieve antibacterial activity. Electrostatic interactions between the positively-charged QAC head and the negatively charged bacterial cellular membrane are followed by penetration of the side alkyl chains into the interface area disturb bacterial lipid bilayer membranes and leakage of the cellular content. ${ }^{29} \mathbf{2 b}$ with 


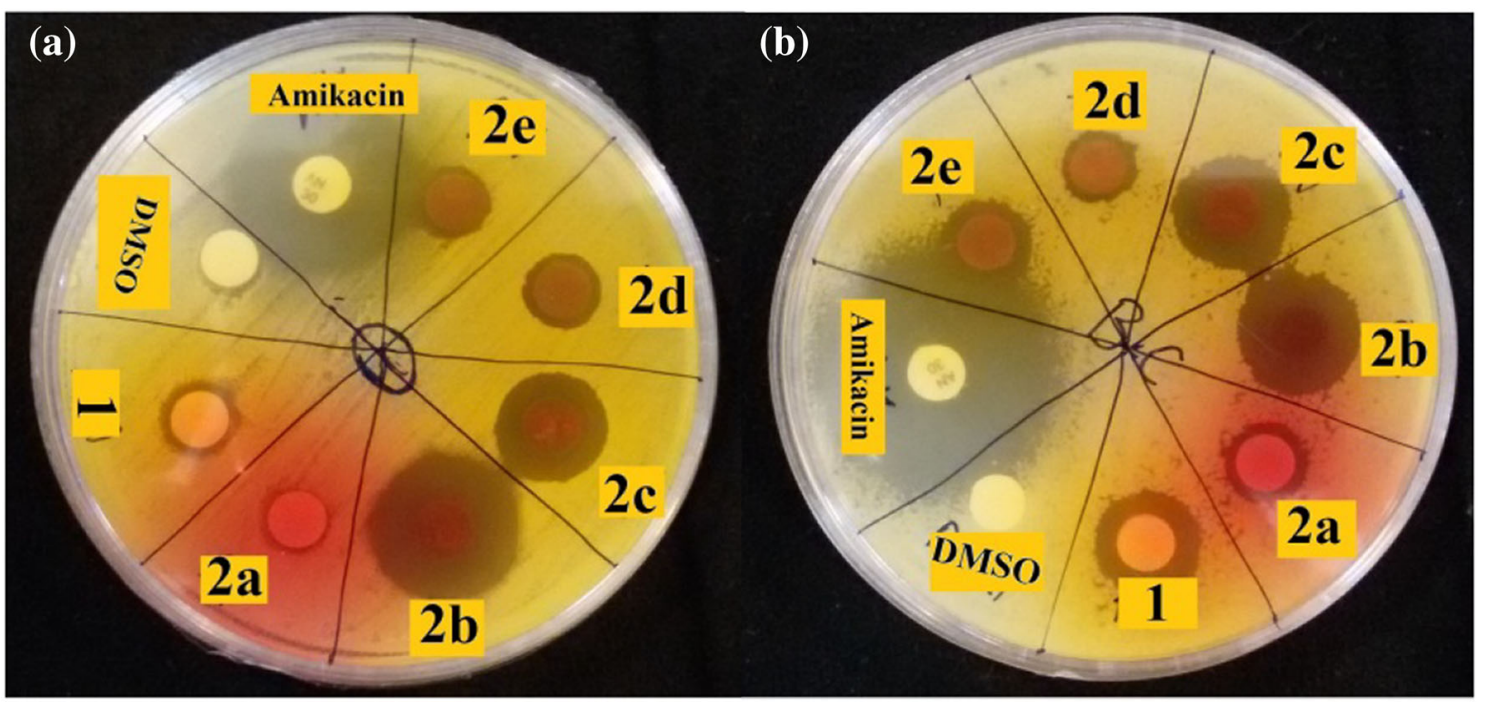

Figure 4. The antibacterial activity test against (a) S. aureus and (b) B. cereus.

Table 3. In vitro antimicrobial activities of synthesized compounds.

\begin{tabular}{lcccc}
\hline & \multicolumn{2}{c}{ Zone of inhibition $(\mathrm{mm})$ against bacteria } \\
\cline { 2 - 5 } Compound $(30 \mu \mathrm{g} / \mathrm{disc})$ & S. aureus & B. cereuss & E. coli & K. pneumonia \\
\hline $\mathbf{1}$ & 8 & 10 & - & - \\
$\mathbf{2 a}$ & 7 & 9 & - & - \\
$\mathbf{2 b}$ & 17 & 14 & - & - \\
$\mathbf{2 c}$ & 13 & 13 & - & - \\
$\mathbf{2 d}$ & 9 & 9 & - & - \\
$\mathbf{2 e}$ & 9 & 10 & - & - \\
Amikacin & 22 & 30 & 22 & 18 \\
\hline
\end{tabular}

Table 4. Minimal inhibitory concentration of $\mathbf{2 b}(\mu \mathrm{g} / \mathrm{mL})$.

\begin{tabular}{lll}
\hline Compound & S. aureus & B. cereuss \\
\hline $\mathbf{2 b}$ & $\mathrm{MIC}(\mu \mathrm{g} / \mathrm{mL})$ \\
& 31.2 & 62.5 \\
\hline
\end{tabular}

decyl group displays the highest activity; the results are listed in Table 3.

Since compound $\mathbf{2 b}$ shows the highest activity, it was further assessed to find minimal inhibitory concentration (MIC) against $S$. aureus and B. cereus, by broth macro-dilution method; the results are reported in Table 4.

Compounds 2a-e were also evaluated for their scavenging activity by diphenyl picrylhydrazyl (DPPH) method. The results are presented in Table 5. A review of the data reveals that all azo pyridinium compounds show much better free radical inhibition compared to the corresponding azo ligand. The highest scavenger activity was observed in 2a. Scavenging activity of all compounds was lower than the standard ascorbic acid with $97.04 \%$ activity. The $50 \%$ of inhibition values $\left(\mathrm{IC}_{50}\right)$ ranged from 1.58 to $9.28 \mathrm{mg} / \mathrm{mL}$. 2a showed the most potent activity with the $\mathrm{IC}_{50}$ value of $1.58 \mathrm{mg} / \mathrm{mL}$; the results are listed in Table 6. It is reported that creation of the positive charge density by the formation of QACs improves the antioxidant properties. ${ }^{30,31}$ Compounds 2 a-e have a hydroxyl group, and antioxidant activity can be strongly dependent on the position and number of hydroxyl groups due to the ability to produce active hydrogen. ${ }^{32,33}$ It has been proposed that the scavenging activity may be associated to the reaction of DPPH-radical with active hydrogen and QACs as an electron-withdrawing group can reduce the dissociation energy of $\mathrm{O}-\mathrm{H}$ and it facilitated the active hydrogen production. ${ }^{34}$

\section{Conclusions}

New alkyl pyridinium salts (2a-e) were prepared and characterized by various spectral techniques. The structural studies by UV-Vis and ${ }^{1} \mathrm{H}$ and ${ }^{13} \mathrm{C}$ NMR indicated keto-enol tautomerism with dipole moment changes 
Table 5. Antioxidant activity of $\mathbf{1}$ and $\mathbf{2 a}-\mathbf{e}(\%)$.

\begin{tabular}{lccccccc}
\hline & \multicolumn{6}{c}{ DPPH Scavenging $(\%)$} \\
\cline { 2 - 7 } Concentration $1000(\mu \mathrm{g} / \mathrm{mL})$ & $\mathbf{1}$ & $\mathbf{2 a}$ & $\mathbf{2 b}$ & $\mathbf{2 c}$ & $\mathbf{2 d}$ & $\mathbf{2 e}$ & Vitamin C \\
\hline & 2.65 & 33.33 & 6.85 & 18.85 & 10.90 & 7.48 & 97.04 \\
\hline
\end{tabular}

Table 6. The $\mathrm{IC}_{50}$ for antioxidant activity of $\mathbf{1}$ and 2a-e.

\begin{tabular}{lc}
\hline Compounds $(\mu \mathrm{g} / \mathrm{mL})$ & $\mathrm{IC}_{50}(\mathrm{mg} / \mathrm{mL})$ \\
\hline $\mathbf{1}$ & 19.25 \\
$\mathbf{2 a}$ & 1.58 \\
$\mathbf{2 b}$ & 9.28 \\
$\mathbf{2 c}$ & 8.87 \\
$\mathbf{2 d}$ & 6.66 \\
$\mathbf{2 e}$ & 3.19 \\
Vitamin C & 0.05 \\
\hline
\end{tabular}

in $\mathbf{2 a - e}$ being dependent on the nature of solvent and $\mathrm{pH}$. The NMR, UV-Vis absorption spectra and quantum chemical calculations of 2a-e support a resonant structure compared to the azo precursor. The compounds 2a-e show moderate-to-good antibacterial and antioxidant activity. The results show that the carbon chain is necessary to achieve antibacterial activity. The compounds $\mathbf{2 b}$ and $\mathbf{2 a}$ with decyl and methyl groups, respectively, exhibit the best antibacterial and antioxidant activity.

\section{Supplementary Information (SI)}

All additional information pertaining to experimental data and characterization of $\mathbf{1}$ and $\mathbf{2 a}-\mathbf{e}$ using FT-IR, UV-Vis, ${ }^{1} \mathrm{H},{ }^{13} \mathrm{C}$ and mass spectra are given in Figures S1-S25. The representative geometries of the optimized conformers of $\mathbf{2 a}$ are given in S26; the list of the selected data for optimized structures of 2a conformers are shown in Table S1. Supplementary Information is available at www.ias.ac.in/chemsci.

\section{Acknowledgements}

We are grateful to the Lorestan University for financial support of this work.

\section{References}

1. Merino E 2011 Synthesis of azobenzenes: The coloured pieces of molecular materials Chem. Soc. Rev. 403835

2. Zollinger H 2003 In Color Chemistry: Syntheses, Properties, and Applications of Organic Dyes and Pigments (Weinheim: Wiley)

3. Zollinger H (Ed.) 1961 In Azo and Diazo Chemistry: Aliphatic and Aromatic Compounds (New York: Interscience publishers)
4. Ghasemian M, Kakanejadifard A, Azarbani F, Zabardasti A and Kakanejadifard S 2014 The triazine-based azo-azomethine dyes; spectroscopy, solvatochromism and biological properties of 2, 2'-( (2, 2'-(6-methoxy-1, 3, 5-triazine-2, 4-diyl) bis (oxy) bis (2,1-phenylene)) bis (azan-1-yl-1-ylidene) bis (methan1-yl-1-ylidene)) bis (4-phenyldiazenyl) phenol J. Mol. Liq. 19535

5. Kakanejadifard A, Azarbani F, Zabardasti A, Kakanejadifard S, Ghasemian M, Esna-ashari F, Omidi S, Shirali S and Rafieefar M 2013 The synthesis, structural characterization and antibacterial properties of some 2-((4-amino-1, 2, 5-oxadiazol-3-ylimino) methyl)-4-(phenyldiazenyl) phenol Dyes Pigments 97 215

6. Abuo-Melha H and Fadda A 2012 Synthesis, spectral characterization and in vitro antimicrobial activity of some new azopyridine derivatives Spectrochim. Acta A 89123

7. Vallabhajosula S 2011 Positron emission tomography radiopharmaceuticals for imaging brain beta-amyloid Semin. Nucl. Med. 4283

8. Marmion D M 1991 In Handbook of US Colorants: Foods, Drugs, Cosmetics, and Medical Devices (Weinheim: Wiley)

9. Kucharski T J, Ferralis N, Kolpak A M, Zheng J O, Nocera D G and Grossman J C 2014 Templated assembly of photoswitches significantly increases the energystorage capacity of solar thermal fuels Nat. Chem. 6441

10. Gorostiza P and Isacoff E Y 2008 Optical switches for remote and noninvasive control of cell signaling Science 322395

11. Saphier S, Haft A and Margel S 2012 Bacterial reduction as means for colonic drug delivery: Can other chemical groups provide an alternative to the azo bond? J. Med. Chem. 5510781

12. Towns A 1999 Developments in azo disperse dyes derived from heterocyclic Diazo Compon. 423

13. Seferoglu Z and Ertan N 2007 Synthesis and spectral properties of new hetarylazo indole dyes Russian J. Org. Chem. 431035

14. Zelenitsky S A and Zhanel G G 1995 Phenazopyridine in urinary tract infections Ann. Pharmacother. 30866

15. Merianos J J 1991 Quarternary ammonium antimicrobial compound. In Disinfection, Sterilization and Preservation, 4th edn. (Philadelphia: Lea \& Feiber) p. 225

16. Yadav P, Kumar B, Gautam H K and Sharma S K 2017 Synthesis and antibacterial activity screening of quaternary ammonium derivatives of triazolyl pyranochromenones J. Chem. Sci. 129211

17. Rhein L 1997 In vitro interactions: biochemical and biophysical effects of surfactantson skin In Surfactants in Cosmetics $2^{\text {nd }}$ edn. Martin Reiger (Ed.) (New York: Routledge) Ch. 18 
18. Shelton R, Campen M v, Tilford C, Lang H, Nisonger L, Bandelin F and Rubenkoenig H 1946 Quaternary ammonium salts as germicides. I. Non-acylated quaternary ammonium salts derived from aliphatic amines $1 \mathrm{~J}$. Am. Chem. Soc. 68753

19. Odabaşoğlu M, Albayrak Ç, Özkanca R, Aykan F Z and Lonecke P 2007 Some polyhydroxy azo-azomethine derivatives of salicylaldehyde: Synthesis, characterization, spectroscopic, molecular structure and antimicrobial activity studies J. Mol. Struct. 84071

20. Bauer A, Kirby W, Sherris J C and Turck M 1966 Antibiotic susceptibility testing by a standardized single disk method Am. J. Clin. Pathol. 45493

21. Jorgensen J H 1993 Methods for dilution antimicrobial susceptibility tests for bacteria that grow aerobically: Approved standard: NCCLS document M7-A3 Nccls

22. Shimada K, Fujikawa K, Yahara K and Nakamura T 1992 Antioxidative properties of xanthan on the autoxidation of soybean oil in cyclodextrin emulsion J. Agric. Food Chem. 40945

23. Frisch M, Trucks G, Schlegel H, Scuseria G, Robb M, Cheeseman J, Montgomery Jr J, Vreven T, Kudin K and Burant J 2004 Gaussian 03, revision c. 02 (Wallingford, CT: Gaussian. Inc.)

24. Dennington R, Keith T, Millam J, Eppinnett K, Hovell W L and Gilliland R 2009 GaussView (Shawnee Mission: Semichem Inc)

25. Runge E and Gross E K 1984 Density-functional theory for time-dependent systems Phys. Rev. Lett. 52997

26. Bauernschmitt R and Ahlrichs R 1996 Treatment of electronic excitations within the adiabatic approximation of time dependent density functional theory Chem. Phys. Lett. 256454
27. Zakerhamidi M, Nejati K, Sorkhabi S G and Saati M 2013 Substituent and solvent effects on the spectroscopic properties and dipole moments of hydroxyl benzaldehyde azo dye and related Schiff bases J. Mol. Liq. 180 225

28. Xia W, Huang C, Ye X, Luo C, Gan L and Liu Z 1996 Photochromic and electrochemical properties of a Novel Azo pyridinium compound and its Langmuir-Blodgett films J. Phys. Chem. 1002244

29. Denyer S P 1995 Mechanisms of action of antibacterial biocides Int. Biodeter. Biodegr. 36227

30. Luan F, Wei L, Zhang J, Tan W, Chen Y, Dong F, Li $\mathrm{Q}$ and Guo Z 2018 Preparation and characterization of quaternized chitosan derivatives and assessment of their antioxidant activity Molecules 23516

31. Liu J, Sun, H, Dong F, Xue Q, Wang G, Qin S and Guo Z 2009 The influence of the cation of quaternized chitosans on antioxidant activity Carbohydr. Polym. 78 439

32. Abdel-Aziz M, Abuo-Rahma G E-D A and Hassan A A 2009 Synthesis of novel pyrazole derivatives and evaluation of their antidepressant and anticonvulsant activities Eur. J. Med. Chem. 443480

33. Özil M, Parlak C and Baltaş N 2018 A simple and efficient synthesis of benzimidazoles containing piperazine or morpholine skeleton at C-6 position as glucosidase inhibitors with antioxidant activity Bioorg. Chem. 76 468

34. Chen $\mathrm{T}, \mathrm{Xu} \mathrm{P}$, Zong $\mathrm{S}$, Wang $\mathrm{Y}, \mathrm{Su} \mathrm{N}$ and $\mathrm{Ye} \mathrm{M}$ 2017 Purification, structural features, antioxidant and moisture-preserving activities of an exopolysaccharide from Lachnum YM262 Bioorg. Med. Chem. Lett. 27 1225 